\title{
Improving Educational Outcomes by Providing Educational Services through Mobile Technology
}

\author{
http://dx.doi.org/10.3991/ijim.v7i1.2287
}

\author{
Hosam F. El-Sofany ${ }^{1}$, Turky Al-Turki ${ }^{1}$, Hasan El-Howimelm ${ }^{1}$, Amjad Al-Sadoon ${ }^{1}$, and Samir A. El-Seoud ${ }^{2}$ \\ ${ }^{1}$ Arab East Colleges for Graduate Studies, Riyadh, Kingdom of Saudi Arabia \\ ${ }^{2}$ British University in Egypt-BUE, Cairo - Egypt
}

\begin{abstract}
The use of Computers, Networks, and Internet has successfully enabled educational institutions to provide their students and instructors with various online educational services. With the recent developments in M-learning and mobile technology, further possibilities are emerging to provide such services through mobile devices such as mobile phones and PDAs. By providing the educational services using wireless and mobile technologies, the educational institutions can potentially bring great convenience to those off-campus students who do not always have time to find Internet enabled computers to get the important educational information from their academic institutions. With the mobile or M-educational services, both the students and the instructors can access the services anytime and anywhere they want. This paper discusses those M-educational services that can be moved to the mobile platform and then presents the system prototype and architecture that integrate these services into the mobile technology platform. The paper will conclude with a description of the formative evaluation of the system prototype.
\end{abstract}

Index Terms-Mobile Applications and Services, Computer Networks, Mobile Telephony, Educational Applications, Elearning, M-learning.

\section{INTRODUCTION}

The number of mobile users is rapidly growing, so the demand for mobile services is becoming stronger and more diversified. Especially in the universities, the demands for mobile services that facilitate the educational services provided by the university are represent a strong challenge. Actually the widespread mobile technology is the digital cellular telephony and is emerging the need to integrate mobile telephony services and computer network services. The integration between information services (e.g. databases), notification services (e.g. E-mail, alarm systems) and telecommunications infrastructure (e.g. GSM, Fax, etc.) is one of the strategic issues to satisfy mobility needs [7]. Different kinds of protocols have been developed in recent years to permit the access to Internet Service from a mobile phone. In particular WAP (Wireless Application Protocol) became the "de facto" standard for this kind of application. Actually there are different reasons, for example different costs and diffusion of terminals that are WAP compliant, to prefer hybrid systems in which are embedded both WAP based service and SMS (Short Message Service) based services [8].

Use of WAP or SMS based tests through PDA, PALM, mobile phone or computer in higher education has been promoted due to the fact that they support the learning process of the students, offer exercise media and provide the opportunity to test the expected learning level achieved [4-6]. However, as stated by Homan and Wood [20], the cost of such services for the students should be decreased so that these new learning media can be widely used. Homan and Wood analyzed the achievement level and views of the students on the paper based and mobile based tests in internet based wireless and traditional classrooms. They found that there was no significant difference between students' achievement level and the students had positive views about the wireless test conducted on PDA, however the students stated that they wanted to use the infrastructural opportunities of the university, instead of their own devices [1].

Because most students today have some sort of internetenabled mobile device (3G cell phone or PDA, smart phone), M-educational services system provides these users with fast, straightforward access to their academic lives. M-educational system has space for greater applications tailored to its strong points. For example, it has the possibility of sending notifications to the user whenever the course's instructor makes certain announcement, therefore notifying students of things such as course cancellations or room changes without risking the students not checking the system on their own.

The literature on M-learning points to a variety of benefits that mobile phones could have on the educational sector. For heuristic purposes, the impacts of mobile phones on educational outcomes that are identified in the M-learning literature can be classified into two broad categories. On the one hand, mobiles supposedly impact educational outcomes by improving access to education while maintaining the quality of education delivered. On the other hand, mobiles purportedly impact educational outcomes by facilitating alternative learning processes and instructional methods collectively known as new learning [2].

Our research study aims to introduce the system prototype and architecture that provide the educational services to the students through their mobile phone devices. Using short message service (SMS) services from the GSM network (Global System for Mobile communications). The student will be able to inquire all the information he need such as: the registration and admission date, open courses for the current semester, grades, registered course, short course preview, sessions period and class room for each course, course instructor, course prerequisites, and exams date, time and location. We choose SMS services because it is the most familiar service in the GSM network and it correspondent with all mobile phone brands. This 
PAPER

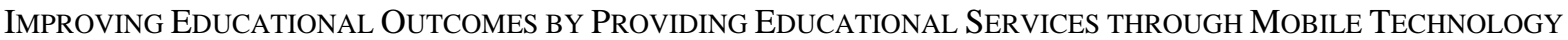

system will increase the portability and accessibility of the registration system. The proposed architecture will used to integrate mobile telephony both with deferred applications, using an SMS Interface. For the immediate applications a WAP Proxy system can be used but also the SMSInterface can give access to immediate applications to user with a no-WAP terminal.

The paper is organized as follows: in section two we present condensed survey and previous works related to the M-learning and M-educational services. In section three we present some advantages and disadvantages of M-learning. In section four we introduce an overview of mobile technology that consists of mobile devices and wireless communication technologies. In section five we introduce the architecture of the proposed M-educational system. The paper finally concluded in section six with conclusion and future works.

\section{PREvious Works}

Samir Abou El-Seoud et al. presented a mobile learning platform (MLP) connected to a Moodle course management system build, using the Java2 Micro Edition (J2ME), the authors have developed the project in their Mobile Multimedia and Wireless Communication Lab (MMWCL). The MLP used wireless communications (Bluetooth, WI-FI, WIMAX) to connect with the Moodle server. The project applications provided the user with a bundle of services. These services include grades, course schedules, attendance records, course announcements, and university activities, as well as quality assessments [3].

Valk, J., Rashid et al. reviewed the evidence of the role of mobile phone-facilitated M-learning in contributing to improved educational outcomes in the developing countries of Asia by exploring the results of six M-learning pilot projects that took place in the Philippines, Mongolia, Thailand, India, and Bangladesh. In particular, this article examined the extent to which the use of mobile phones helped to improve educational outcomes in two specific ways: 1) in improving access to education, and 2) in promoting new learning. Analysis of the projects indicated that while there is important evidence of mobile phones facilitating increased access, much less evidence exists as to how mobiles promote new learning [2].

Marcelo and Michele in [9], illustrated a number of educational mobile services used by students in a university environment and discussed the patterns of use of these services on campus and other locations of their choice. Impact on learning itself was not measured, nor would it have been possible to measure meaningfully when the devices were used for such diverse purposes. Phoneoptimized content was well used, and there was a clear request from students that more resources be made available in this format, including administrative information from the University. There is no conclusive evidence of the need for a specifically designed suite of tools in addition to those already included in the device, although students would like to send multimedia material of larger size than that allowed on an MMS (Multimedia Messaging Service).

They also illustrated that, greater institutional support is needed in order for the smart phones to be used more fully. Regular updates of timetables and content, as well as adequate training and hardware provision are needed. As more students bring the technology with them to the university, change will most likely be driven by their demands as consumers. It has been shown that the smart phones used in this study did not generate a radical change in students' styles or patterns of learning. As smart phones become a more intrinsic part of everyday life, it is important that these patterns and demands are known and understood.

\section{Advantages ANd DisadvantAges OF M-LEARNing}

M-learning has received a lot of attention in recent years as a growing segment of the educational and instructional technology field. Mobile learning through the use of wireless mobile technology allows anyone to access information and learning materials from anywhere and at any time. As a result, learners have control of when they want to learn and from which location they want to learn. Also, all humans have the right to access learning materials and information to improve their quality of life regardless of where they live, their status, and their culture. Mlearning, through the use of mobile technology, will allow citizens of the world to access learning materials and information from anywhere and at any time. Also, learners do not have to learn what is prescribed to them. They can use the wireless mobile technology for formal and informal learning where they can access additional and personalized learning materials from the Internet or from the host organization. Graduate students who work can use the mobile technology to access course materials and educational information when they need it. Mobile learning having various benefits includes:

M-learning will not replace any form of learning (e.g. classroom learning or E-learning). M-learning is just providing another way of learning using new mobile technology. The strength of M-learning lies in a communication approaches rather than a content approaches (e.g. content creation). Each learning form (or service) has advantages and disadvantages, so the term of blended learning was introduced. Blended Learning refers to mix different learning environments in order to treat disadvantages of one form with advantages of another form. Therefore, it is better to blended M-learning with other forms of learning. Because of M-learning cannot be used as main learning form, but it can be an effective form that can be used in conjunction with other learning forms to improve and facilitate the learning process.

Many advantages and disadvantages related to use mobile technologies for learning have demonstrated in several studies. The key benefits of M-learning include [1013]:

- Interaction: Learners can interact with others and/or instructors without restriction of time and place.

- Flexibility: M-learning can be just-in-time learning where learners can actually access learning and educational services at the place and time that they need it.

- Learner can take notes directly into the device in outdoor lessons, either by typed, handwritten or voice.

- Portability: PDAs or Smart phones holding notes and eBooks are lighter, less bulky and easier to carry than bags full of files, paper and textbooks, or even laptops. 
- Enhances knowledge: contents and knowledge are adapting to meet individual needs and delivered ondemand.

- Mobile learning helps learners to improve their literacy and numeracy skills and to recognize their existing abilities.

- Mobile learning can be used to encourage both independent and collaborative learning experiences

- Mobile learning helps learners to identify areas where they need assistance and support.

- Mobile learning helps to combat resistance to the use of ICT and can help bridge the gap between mobile phone literacy and ICT literacy.

- Mobile learning helps to remove some of the formality from the learning experience and engages reluctant learners.

- Mobile learning helps learners to remain more focused for longer periods.

- Mobile learning helps to raise self-esteem.

- Mobile learning helps to raise self-confidence.

On the other hand, the defects (disadvantages) of Mlearning include:

- Limit of devices capacities such as (small screens, memory size and computing power).

- Lack of common operating system and application programs like browsers.

- Wireless networks may down with a larger number of students when using it.

\section{IV.MOBILE TECHNOLOGY OVERVIEW}

Mobile technology consists of mobile devices and wireless communication technologies. We firstly introduce an overview of general wireless communication technologies that can be used in M-learning systems.

\section{A. Wireless Communication Technologies}

\section{Global System for Mobile Communications (GSM)}

GSM is a worldwide mobile telephony system. GSM offers the best voice quality of any current digital wireless standard. GSM provides voice mail, high-speed data, fax, paging and short message services capabilities, as well as secure communication $[14,16]$.

\section{General Packet Radio Service (GPRS)}

GPRS is used for various data applications on phones, including Wireless Application Protocol (WAP), Multimedia Messaging Service (MMS), and software that connect to the Internet. We can say that, any network connection that is not voice or text messaging uses a data connection like GPRS. GPRS provides about four times greater speed than GSM systems [15].

\section{Third Generation (3G)}

3G is mobile phone standards and technologies targeting to multimedia communication through cell phone or smart phones. It supports increased bandwidth and high data transfer rates compared to 2 or 2.5G to allow internet browsing and exchange of audio and video files. In 3G, mobile phones became mobile devices combining a camera, video camera, stereo, MP3 player and radio into one device $[17,18]$.
TABLE I.

SHOWS A COMPARISON BETWEEN M-LEARNING AND E-LEARNING [13].

\begin{tabular}{|l|l|}
\hline \multicolumn{1}{|c|}{ M-learning } & \multicolumn{1}{c|}{ E-learning } \\
\hline $\begin{array}{l}\text { It can be used anywhere at any } \\
\text { time. }\end{array}$ & $\begin{array}{l}\text { Partially it can be used anywhere } \\
\text { at any time. }\end{array}$ \\
\hline $\begin{array}{l}\text { Most mobile devices have lower } \\
\text { prices than Desktop (PCs). }\end{array}$ & $\begin{array}{l}\text { Desktop (PCs) are more expensive } \\
\text { than mobile devices. }\end{array}$ \\
\hline $\begin{array}{l}\text { Mobility: mobile devices are } \\
\text { smaller in size and lighter in } \\
\text { weight than Desktops. }\end{array}$ & $\begin{array}{l}\text { Desktops are not portable. They } \\
\text { are not easily carried around due to } \\
\text { their heavy weight. }\end{array}$ \\
\hline $\begin{array}{l}\text { Number of mobile users greater } \\
\text { than number of PCs users }\end{array}$ & $\begin{array}{l}\text { Number of PCs users less than } \\
\text { number of mobile users }\end{array}$ \\
\hline More easily lost or stolen. & Less easily lost or stolen \\
\hline Poor learning contents & $\begin{array}{l}\text { Rich learning contents (e.g. 3d } \\
\text { animations) }\end{array}$ \\
\hline $\begin{array}{l}\text { Rich communication technolo- } \\
\text { gies (e.g. SMS, MMS, Bluetooth, } \\
\text { etc) }\end{array}$ & Poor communication technologies \\
\hline
\end{tabular}

TABLE II.

SHOWS A COMPARISON BETWEEN EXISTING WIRELESS TECHNOLOGIES [13].

\begin{tabular}{|c|l|l|l|l|}
\hline & $\begin{array}{c}\text { Transfer } \\
\text { Rate } \\
(\mathbf{M b} / \mathbf{s})\end{array}$ & $\begin{array}{c}\text { Range } \\
(\sim \text { meters })\end{array}$ & $\begin{array}{c}\text { Frequency } \\
\text { Band } \\
\mathbf{( G H z )}\end{array}$ & $\begin{array}{c}\text { Number of } \\
\text { users }\end{array}$ \\
\hline Bluetooth & $1-2$ & $10-100$ & 2.4 & Dozens \\
\hline WiFi & $10-54$ & 100 & 2.4 & Dozens \\
\hline GPRS & 0.17 & 30000 & 1.8 & Thousands \\
\hline 3G & $256 \mathrm{kbps}$ & $>1609344$ & Varies & Thousands \\
\hline WiMax & $10-54$ & 49889 & $2-11$ & Thousands \\
\hline
\end{tabular}

\section{Wireless Fidelity (Wi-Fi)}

$\mathrm{Wi}-\mathrm{Fi}$ is a wireless local area network (WLAN). Wi-Fi is technology based on the Institute of Electrical and Electronics Engineers' (IEEE) 802.11family of standards. $\mathrm{Wi}-\mathrm{Fi}$ is a wireless network uses radio waves that communicate in two ways. A centralized network with access point, called infrastructure network and decentralized network without access point, called ad-hoc network. Wi$\mathrm{Fi}$ is used for a variety of applications. One of the most common application is home and business WLAN where it can cover around $100 \mathrm{~m}$ with data transfer rate between 10 - 54 Mbps [19, 20].

5. Worldwide Interoperability for Microwave Access (WiMax)

WiMax provides high speed internet connection for a large number of users over a large area. WiMax can cover range around 31 miles and its data transfer rate between $10-54 \mathrm{Mbps}$. If there are too many users connected to WiMax at the same time, the range will be limited and speed lowered [21, 22].

\section{Short Message Service (SMS)}

SMS is the simplest of all the technologies available in the mobile environment. SMS allows single short messages of up to 160 characters to be passed between mobile phones, fax machines or email addresses. Messages are sent along a mobile phone network, and must pass through an SMS centre which handles and manages the messages. SMS is used in an M-learning scenario for dealing with variety of activities such as asking questions, 
providing answers, information delivery and providing feedback [23].

\section{Multimedia Message Service (MMS)}

MMS is a more advance technology than SMS which enables the sending and receiving multimedia messages that include multimedia objects (images, audio, video, rich text) between mobile phones. MMS content is longer than SMS and transport on WAP, GPRS or 3G. MMS can also be sent from a mobile phone to an email address [24].

\section{B. Mobile Devices}

The M-learning is impossible without the use of the mobile devices. They vary significantly in their abilities, sizes and prices. The common ability which united them is their mobility and possibility to make wireless connections. Mobile devices can be defined as any electronic devices that are small enough to fit in a shirt or jacket pocket. It would not include laptops, as while they are portable, they are not mobile. Mobile devices should fit in your pocket [13].

\section{1) Cell Phone}

A cell phone is an electronic telecommunication mobile device. Cell phones commonly named as mobile phones or cellular phones. A cell phone supports voice communication and SMS. The cellular phones from the higher class can access internet via WAP or GPRS technologies. They also can be used to send and receive MMS. A cell phone prices are decreasing continuously [25].

\section{2) $P D A$}

A Personal Digital Assistant (PDA) is pocket-sized computers that fits in hand and has a touch screen or a small keyboard. PDAs support voice communication, fax capability and email service via a wireless network connection. PDAs support software applications such as internet explorer (IE) and calendar. PDAs have evolved and incorporate cell phone and $3 G$ functions. New PDAs can connect to internet with faster speed via $3 \mathrm{G}$ and WiFi or WiMax. Most PDAs have Bluetooth and the main operating systems used are Palm OS and Microsoft Pocket PC OS [26, 27].

\section{3) Smart Phone}

A smart phone is a mobile device which combines cell phone and PDA functions. They have smaller sizes than PDA and bigger than cellular phones. Smart phones include backlit color screen, Wi-Fi, Bluetooth, large RAM, large ROM and internet browsers. Smart phone use advanced operating systems (e.g. Symbian, Windows Mobile, etc) which can support advanced applications. It is also possible to insert memory card. Smart phones have potential to be successfully used in the M-learning field $[28,29]$.

\section{4) Tablet $P C$}

Tablet PC are one of the newest mobile devices. They also have full range of capabilities as personal computers. Some of them haven't keyboard but have software to recognize handwritten text and voice-recognition features that will continue to evolve and improve. Because of their large screens and high resolutions, Tablets PCs are good candidates for delivering online courses. They also offer rich data capture and image manipulation features, which can be useful for learning applications [30].

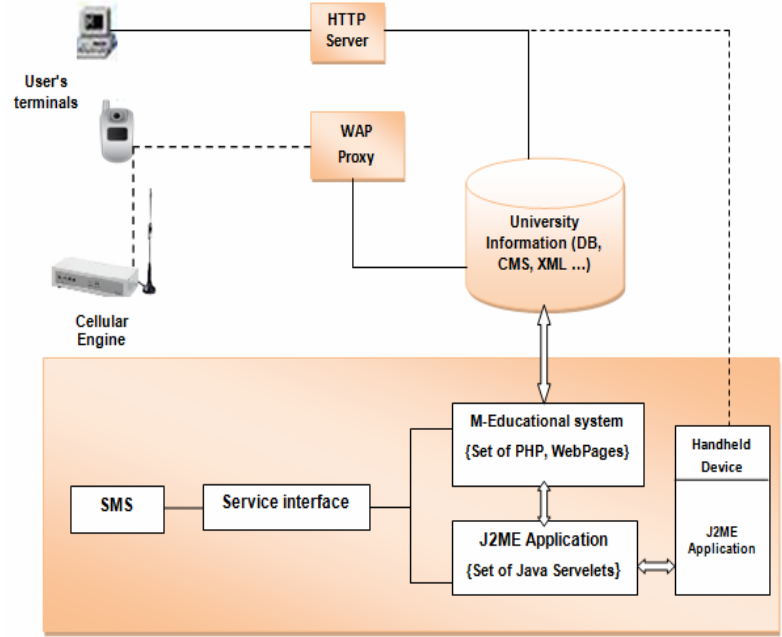

Figure 1. The general architecture of the M-education system

\section{SYSTEM ARCHITECTURE}

The system architecture is composed mainly of three components: the J2Me application, the interface between the J2ME application and the project server, and finally an instance of M-educational system server for back-end support and integration.

Figure 1, states clearly the system overview of the proposed M-educational services system. The mobile "handheld" device is composed of group of J2ME application that is designated to connect to J2ME application server to attain the provided services. The second component in our system is shortly an interface to match between the mobile applications and the M-educational server. This component is in charge of translating the mobile application requests into suitable format for M-educational system.

Various optimization techniques are applied on the mobile application in order to attain a good amount of mobile limited resource utilization. In addition, a novel technique is conducting to achieve high percentage of load balance on the M-educational system side. The load balance will guarantee a high degree of robustness and stable behavior for the whole platform give the great amount of users (students) who are using the system [31, 32].

The provided services include:

\section{A. Security and confidentiality of personal information}

- The possibility of changing the Username and Password.

- Displaying the user information and ability to update them through the system.

\section{B. Registration}

- Drop registered courses and/or add new courses.

- Displaying the weekly schedule (Time table).

- Displaying the whole schedule and the open courses/sections.

- Calculating and displaying the registration fee for academic term or for registered courses.

- Displaying the registration status for the student (continuous, withdraw ...).

- Displaying the historical record of student registration, and what has been registered and /or learned. 


\section{Query for student information and displaying the following}

- The grade of midterm and final exams (if any).

- The details of the grades (i.e., homework, project, quizzes, ...).

- The curriculum of the program, study plan, number of hours and courses description.

- The ability to obtain the academic transcript of the student from the registration office.

\section{Financial services for student}

- Displaying the summary of financial account.

- Displaying the deposit records of the student.

A pilot study is conducting to measure the efficiency of the proposed system. Expected results are to support our basic provided service usability and importance. In addition, a comparative study is taking place to cross examine the platform end-to-end efficiency.

\section{VI.CONCLUSION AND FUTURE WORKS}

By providing the educational services using wireless and mobile technologies, the educational institutions can potentially bring great convenience to those off-campus students who do not always have time to find Internet enabled computers to get the important educational information from their academic institutions. With the mobile or M-educational services, both the students and the instructors can access the services anytime and anywhere they want. The paper introduced the architecture of Meducational system that provides the educational services to student through the mobile devices. The study categorized the proposed educational services into four categories that include: 1) Security and confidentiality of personal information, 2) Registration, 3) Query for student information and displaying the following, and 4) Financial services for student.

To continue our work in the future, we will try to enhance the educational aspects of the mobile services by developing and implementing various solutions to specific problems we have identified based on our observations and the data we have collected from the students. Our future efforts will continue to refine both the technology and activities for providing learners with more meaningful experiences with regard to the use of smart phones in university settings.

\section{ACKNOWLEDGMENT}

The authors acknowledge the full support received from Arab East Colleges for Graduate Studies, especially they very thankful to Professor Dr. Abd Allah Alfaisal, Dean of the Colleges, for his encouragement and support.

\section{REFERENCES}

[1] Hosam F. El-Sofany, and Samir A.El-Seoud, "Towards Development of Web-based Assessment System Based on Semantic Web Technology". International Journal of Interactive Mobile Technologies (iJIM), Vol. 5, Issue 1, Pages 22-30, http://dx.doi.org/10.3991/ijim.v5i1.1439, January 2011.

[2] Valk, J., Rashid, A. T., \& Elder, L. Using Mobile Phones to Improve Educational Outcomes: An Analysis of Evidence from Asia. International Review of Research in Open and Distance Learning, 11(1), 117-140, March 2010.
[3] Samir Abou El-Seoud, Ashraf M.A. Ahmad and Hosam Farouk El-Sofany, "Mobile Learning Platform Connected to Moodle using J2ME", International Journal of Interactive Mobile Technologies (iJIM), Volume 3, Issue 2, P: 46-54, http://dx.doi.org/10.3991/ijim.v3i2.751, April 2009.

[4] Dawabi P, Wessner M, Neuhold E. Using mobile devices for the classroom of the future. Proceedings of Mlearn 2003 Conference on Learning with Mobile Devices, London pp. 14-15, 2003.

[5] Scornavacca E, Marshall S. TXT-2-LRN: Improving students' learning experience in the classroom through interactive SMS Proceedings of the 40th Hawaii International Conference on System Sciences, Hawaii, 2007.

[6] Wentling L, Park J, Peiper C. Learning gains associated with annotation and communication software designed for large undergraduate classes. J. Comp. Assist. Learn. 23(1), 36-46, 2007. http://dx.doi.org/10.1111/j.1365-2729.2007.00197.x

[7] Messerschmitt, D.G. "The convergence of telecommunications and computing: What are implications today?', Proceeding of the IEEE, vol. 84, no. 8, pp. 1167-1186, Aug. 1996. http://dx.doi.org/10.1109/5.533962

[8] Fasbender; A., Reichert; F., Geulen; J., Hjelm; J. And Wierlemann, T. "Any network, any terminal, anywhere", IEEE Personal Communications, pp. 22-30, Apr. 1999.

[9] Marcelo Milrad, and Michele H. Jackson, "Designing and Implementing Educational Mobile Services in University Classrooms Using Smart Phones and Cellular Networks ". Int. J. Engng Ed. Vol. 24, No. 1, pp. 84-91, 2008.

[10] Balasundaram S. R. and Ramadoss B., SMS for QuestionAnswering in the m-Learning Scenario. Journal of Computer Science, 3(2): p. 119-121, 2007. http://dx.doi.org/10.3844/ jcssp.2007.119.121

[11] Boyinbode O. K. and Akinyede R. O., MOBILE LEARNING: AN APPLICATION OF MOBILE AND WIRELESS TECHNOLOGIES IN NIGERIAN LEARNING SYSTEM. IJCSNS, 8(11): p. 386, 2008.

[12] Orr G., A Review of Literature in Mobile Learning: Affordances and Constraints, in The 6th IEEE International Conference on Wireless, Mobile, and Ubiquitous Technologies in Education. IEEE. p. 107-111, 2010.

[13] Amr A. M. Abozeid, "Toward the Development of an Adaptive Mobile Learning Environment", MS Thesis, Department of Mathematics, Faculty of Science, Ain Shams University, Cairo, Egypt, 2011.

[14] Egea-Lopez E., Martinez-Sala A., Vales-Alonso J., Garcia-Haro J. and Malgosa-Sanahuja J., Wireless communications deployment in industry: a review of issues, options and technologies. sciencedirect, 2005. 56(1): p. 29-53.

[15] Egea-Lopez E., Martinez-Sala A., Vales-Alonso J., Garcia-Haro J. and Malgosa-Sanahuja J., Wireless communications deployment in industry: a review of issues, options and technologies. Computers in industry, $2005.256(1)$ p. 29. http://dx.doi.org/10.1016/j.compind.2004.10.001

[16] Georgiev T., Georgieva E. and Smrikarov A. M-learning-a New Stage of -Learning. in International Conference on Computer Systems and Technologies. 2006.

[17] J.L Gimenez Lópeza T. Magal Royoa, Jesus García Labordab, F. Garde Calvoa, Methods of adapting digital content for the learning process via mobile devices. Procedia Social and Behavioral Sciences,ScienceDirect, 2009. 1: p. 2673-2677.

[18] Keogh J., The Complete Reference J2ME. Published by McGrawHill OSBORNE Edition, 2003.

[19] 4G Americas. [cited 9-12-2010; Available from: http://www.4gamericas.org/ index.cfm?fuseaction=page \&sectionid $=260$

[20] Zahariadis T., Evolution of the Wireless PAN and LAN standards. Computer Standards \& Interfaces, sciencedirect, 2004. 26(3): p. 175-185.

[21] Jacob S. M. and Issac B., Mobile technologies and its impact-an analysis in higher education context. International Journal of Interactive Mobile Technologies (iJIM), 2008. 2(1).

[22] Malek J., Laroussi M., Derycke A. and Ben Ghezala H., A Context-Aware Approach for Modeling Bijective Adaptations between Context and Activity in a Mobile and Collaborative learn- 
ing. International Journal of Interactive Mobile Technologies (iJIM), 2007. 2(1).

[23] Balasundaram S. R. and Ramadoss B., SMS for QuestionAnswering in the m-Learning Scenario. Journal of Computer Science, 2007. 3(2): p. 119-121. http://dx.doi.org/10.3844/ jcssp.2007.119.121

[24] Lee W. P.,Osman M. A.,Sabudin M.,Sulaiman S.,Zadeh L. A.,Kacprzyk J.,Mastorakis N.,Kuri-Morales A.,Borne P., and Kazovsky L. An Experience on Introducing a Mobile Community Platform: Flying 2 U. in WSEAS International Conference. Proceedings. Mathematics and Computers in Science and Engineering. 2010: World Scientific and Engineering Academy and Society.

[25] Economides A. A. and Nikolaou N., Evaluation of handheld devices for mobile learning. International Journal of Engineering Education, 2008. 24(1).

[26] Houser C., Thornton P. and Kluge D., Mobile learning: cell phones and PDAs for education, in Proceedings of the International Conference on Computers in Education (ICCE’02). 2003, IEEE. p. 1149-1150.

[27] Lindquist D., Denning T., Kelly M., Malani R., Griswold W. G. and Simon B., Exploring the potential of mobile phones for active learning in the classroom. ACM SIGCSE Bulletin, 2007. 39(1): p. 384-388. http://dx.doi.org/10.1145/1227504.1227445

[28] Holzinger A., Nischelwitzer A. and Meisenberger M., Mobile phones as a challenge for M-Learning: Examples for mobile interactive learning objects (MILOs), in Third IEEE International Conference on Pervasive Computing and Communications Workshops (PERCOMW'05). 2005. p. 307-311. http://dx.doi.org/10.1109/ PERCOMW.2005.59

[29] Zheng P. and Ni L. M., The rise of the smart phone. IEEE Distributed Systems Online, 2006. 7(3): p. 1-14.

[30] Mahmoud S. S., A proposed model for distributing e-courses content through mobile technology architectures. International Journal of Human and Social Sciences, 2008. 27: p. 274-289.
[31] Aloysius K. Mok and Weijiang Yu, "TINMAN: A Resource Bound Security Checking System for Mobile Code," In Proceedings of 7th European Symposium on Research in Computer Security (ESORICS 2002), Zurich, Switzerland, pp 178-193, Springer LNCS Volume 2502, October, 2002.

[32] R. Kessl and P. Tvrdík, "Probabilistic Load Balancing Method for Parallel Mining of all Frequent Itemsets", Proceeding (513) Parallel and Distributed Computing and Systems - 2006.

\section{AUTHORS}

Hosam Farouk El-Sofany, Assistant Professor of Computer Science, Arab East Colleges for Graduate Studies, Department of Computer Science, Riyadh, Kingdom of Saudi Arabia. (hosam_elsofany@hotmail.com)

Samir A. El-Seoud, Professor of Computer Science, British University in Egypt-BUE, Faculty of Informatics and Computer Science, Cairo - Egypt. (Samir.elseoud@bue.edu.eg)

Turky, Al-Turki, Student in MSc program, Arab East Colleges for Graduate Studies, Department of Computer Science, Riyadh, Kingdom of Saudi Arabia.

Hasan, El-Howimel, Student in MSc program, Arab East Colleges for Graduate Studies, Department of Computer Science, Riyadh, Kingdom of Saudi Arabia.

Amjad, Al-Sadoon, Student in MSc program, Arab East Colleges for Graduate Studies, Department of Computer Science, Riyadh, Kingdom of Saudi Arabia.

This article is an extended and modified version of a paper presented at the International Conference on Interactive Collaborative Learning (ICL2012), held 26 - 28 September 2012, in Villach, Austria. Received 23 September 2012. Published as resubmitted by the authors 20 December 2012. 